\title{
Mucormicosis rinocerebral en un niño diabético. Tratamiento conservador
}

\author{
ANA CHÁVEZ P. y MARITZA RAHAL E.
}

\section{Rhinocerebral mucormycosis in a diabetic child. Conservative treatment}

A case of rhinosinusitis in a 14 year old diabetic boy, which had not responded to various antibiotic schemes, is presented. The diagnosis of rhinocerebral mucormycosis was late, when there was already intracraneal involvement, which was demostrated by CT scan. Considered out of surgical reach, he was treated with amphotericin B and multiple endoscopical debridements, with a good clinical and image outcome. The diagnosis of mucor was established by direct and histopathological examination which revealed the presence of characteristic hyphae.

Key words: Mucormycosis; Rhinocerebral; Fungal infection; Amphotericin B.

\section{Introducción}

Mucormicosis es una infección oportunista por hongos del orden Mucorales, clase Zygomycetes, muy poco frecuente. La forma clínica más común es la rinocerebral y los pacientes con cetoacidosis diabética constituyen un grupo de riesgo para esta infección ${ }^{1-4}$. El pronóstico de esta infección, hasta hace 20 años era uniformemente fatal, pronóstico que ha mejorado con el diagnóstico precoz, el uso de antifúngicos sistémicos y debridamiento quirúrgico agresivo ${ }^{2-4}$.

Se presenta el caso de un niño con diabetes mal controlada que padeció una mucormicosis rinocerebral diagnosticada tardíamente, a pesar de lo cual respondió satisfactoriamente al tratamiento.

\section{Caso clínico}

Varón, edad 14 años. Antecedentes de diabetes mellitus tipo 1, insulino dependiente desde los 12 años de edad, y de parálisis facial derecha leve, secuela de un accidente de tránsito a los 6 años de vida. Ingresó al hospital de su región, por cefalea de 24 horas de evolución, somnolencia y aumento de glicemia, además de dolor y aumento de volumen en la región maxilar superior derecha comprobándose una cetoacidosis y un absceso dentoalveolar de las piezas dentarias 5 y 6 . Se inició el manejo de la cetoacidosis en UCI, se indicó ampicilina endovenosa y realizó trepanación de las piezas dentarias afectadas.

$\mathrm{Al}$ ingreso se obtuvieron hemograma que mostró neutrofilia, VHS: $29 \mathrm{~mm} / \mathrm{h}$ y PCR $133 \mathrm{mg} / \mathrm{l}$. Una radiografía de cavidades perinasales $(\mathrm{CPN})$ demostró velamiento completo del seno maxilar derecho y parcial del seno frontal.

Al tercer día, por progresión del proceso inflamatorio de la cara, se planteó el diagnóstico de sinusitis maxilar y se cambió tratamiento antimicrobiano a penicilina más cloxacilina y cefotaxima.

El día 6 se realizó exodoncia de restos radiculares de las piezas 5 y 6 ; durante el procedimiento se pesquisó una placa eritematosa de $5 \mathrm{~cm}$ de diámetro en el paladar duro, en relación a las piezas afectadas, lesión que tres días después se había ulcerado; no se comprobó fístula. El cultivo de esta lesión fue positivo a Enterobacter cloacae y Candida sp. Con este informe se cambió nuevamente el tratamiento a penicilina más clindamicina más amikacina y se agregó fluconazol.

El proceso inflamatorio de la cara se mantuvo. Una nueva radiografía y una primera TAC de

Servicio de Pediatría, Hospital Exequiel González Cortés (ACP).

Servicio de Otorrino, Hospital Barros Luco-Trudeau (MRE).

Recibido: 22 agosto 2003

Aceptado: 1 octubre 2003 
CPN mostraron progresión del proceso sinusal, con velamiento del seno maxilar derecho, celdillas etmoidales anteriores y posteriores, seno esfenoidal y parcial del seno frontal. No se observó lesión ósea. Planteado el diagnóstico de pansinusitis derecha, se ajustó el esquema antimicrobiano a ceftriaxona y metronidazol, mientras se mantuvo fluconazol. Al noveno día con este nuevo esquema se realizó una punción del seno maxilar derecho sin obtenerse muestra.

El niño continuó en regulares condiciones generales, con la diabetes descompensada y difícil manejo, y el proceso inflamatorio se extendió comprometiendo toda la hemicara derecha. La parálisis facial derecha aumentó, llegando a ser muy intensa.

El día 34 de hospitalización se realizó una segunda TAC de CPN que reveló mayor extensión del proceso sinusal, describiéndose un aspecto rarefacto de la pared ántero inferior del seno maxilar derecho, sugerente de osteítis por extensión del proceso infeccioso naso-sinusal derecho. Se tomó muestra del seno maxilar para biopsia, la que posteriormente fue informada como proceso inflamatorio crónico.

Por la falta de respuesta a los diversos esquemas antimicrobianos aplicados, el día 41 de evolución se decidió traslado al Hospital Exequiel González Cortés (EGC) con diagnósticos de diabetes mellitus I, proceso pansinusal derecho ¿infeccioso? ¿micótico? ¿tumoral?, úlcera del paladar duro cerrada, parálisis facial derecha antigua.

Al ingreso al Hospital EGC se encontraba en regulares condiciones generales, activo, y al examen presentaba un gran aumento de volumen de la hemicara derecha que comprometía ambos párpados y la mejilla, extendiéndose ligeramente hacia el lado izquierdo, con eritema local, sin dolor. Presentaba una parálisis facial derecha muy intensa y en el paladar se apreciaba una pequeña lesión ulcerada, de fondo limpio.

Se continuó el manejo de la diabetes con insulina cristalina y fue evaluado, de inmediato, por el otorrinolaringólogo (ORL) quien realizó una rinoscopia anterior en la que no se vieron costras y sí se observó una mucosa poco sensible y pálida, con escaso sangramiento. Las biopsias rápidas y cultivo de meato medio, cornete medio y etmoides derecho no detectaron la presencia de hifas. Una tercera TAC de CPN mostró, además del proceso sinusal, compromiso óseo del piso de la órbita derecha y extensión de la lesión hacia el seno cavernoso (Figura 1). El examen ORL y la TAC apoyaron el diagnóstico de mucormicosis, a pesar de no haberse logrado confirmar, por lo que se decidió iniciar tratamiento con anfotericina B.
Dos días más tarde se obtuvieron nuevas muestras las que, tanto en el examen directo como en el estudio histopatológico, revelaron la presencia de hifas aseptadas, con lo que se documentó el diagnóstico de mucormicosis rinocerebral. El cultivo fue negativo.

Ante la evidencia del compromiso intracraneano se consideró fuera de alcance quirúrgico continuando tratamiento con anfotericina $\mathrm{B}$, en dosis de $1,3 \mathrm{mg} / \mathrm{kg} /$ día, la que se debió administrar con hidrocortisona e ibuprofeno para una mejor tolerancia.

A pesar del mal pronóstico el niño evolucionó en condiciones generales estables, conciente, orientado, con persistencia del edema facial y de la parálisis facial derecha.

Ocho días después fue evaluado por neurocirujanos con nueva TAC en la que describieron compromiso sinusal maxilar, etmoidal y esfenoidal, además extensión a la base del cráneo, compromiso del seno cavernoso, estenosis carotídea derecha, compromiso de la región pterigomaxilar y compromiso mastoídeo inicial. Concordaron con la opinión del ORL en que no había posibilidad de resección quirúrgica con límites sanos, por lo que estaba fuera de alcance quirúrgico.

Se continuó tratamiento con insulina y con anfotericina $\mathrm{B}$, realizándose aseos quirúrgicos repetidos, por vía endoscópica.

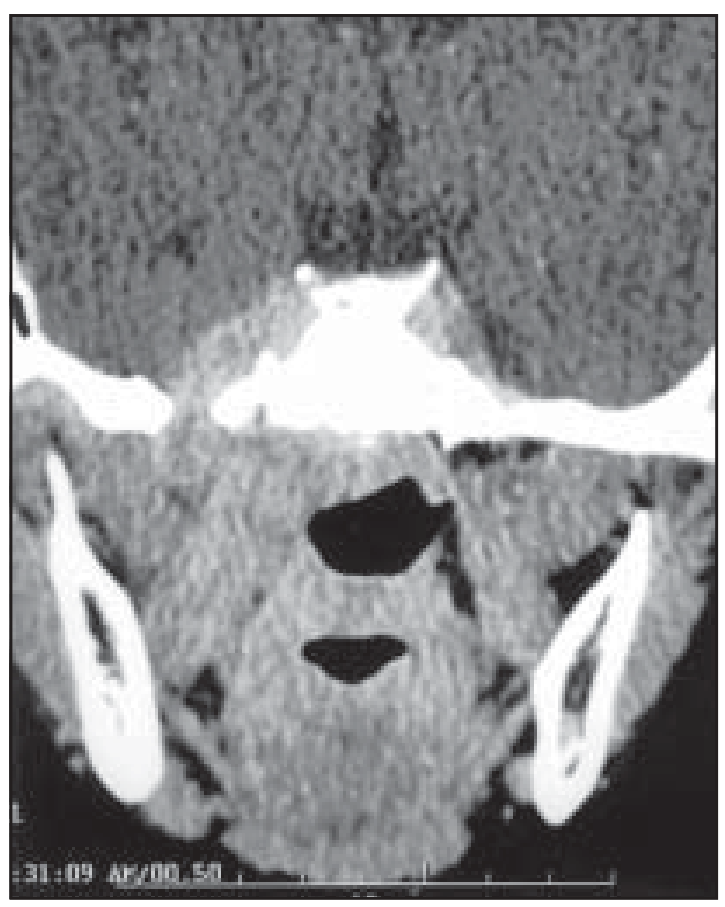

Figura 1. Tomografía axial computarizada de cavidades perinasales. Día 42. Extensión de la lesión hacia seno cavernoso. 
El niño evolucionó en los días siguientes con mejoría progresiva del estado general, disminución del edema de cara, pero persistiendo la parálisis facial; no hubo progresión del compromiso neurológico.

El día 71 se realizó otra TAC que mostró tejido etmoidal derecho residual, una cavidad maxilar amplia y persistencia del compromiso del seno cavernoso (Figura 2). Se realizó nuevo aseo quirúrgico endoscópico en el que se extrajeron espículas óseas y mucosa desvitalizada.

Hasta ese momento, a pesar de la buena evolución clínica e imagenológica, se mantenía la opinión de mal pronóstico del cuadro, dado por la existencia de compromiso intracraneano.

Sin embargo, el niño continuó presentando una evolución favorable, con buen estado general, regresión total del edema de cara y disminución de la parálisis facial, persistiendo sólo la leve parálisis que existía previamente; además se logró finalmente un buen control de la diabetes.

El día 88 completó 2 gramos de anfotericina B y se continuó con la administración 3 veces por semana, hasta completar 3,1 gramos el día 144 (dosis total $90 \mathrm{mg} / \mathrm{kg}$ ). En concomitancia con uso de este antifúngico se constató la elevación de la creatininemia, que llegó a un valor máximo de $1,34 \mathrm{mg} \%$, cifra que se normalizó tras suspender la anfotericina.

Durante el tratamiento, fue sometido además a aseos quirúrgicos seriados, todos por vía endos-

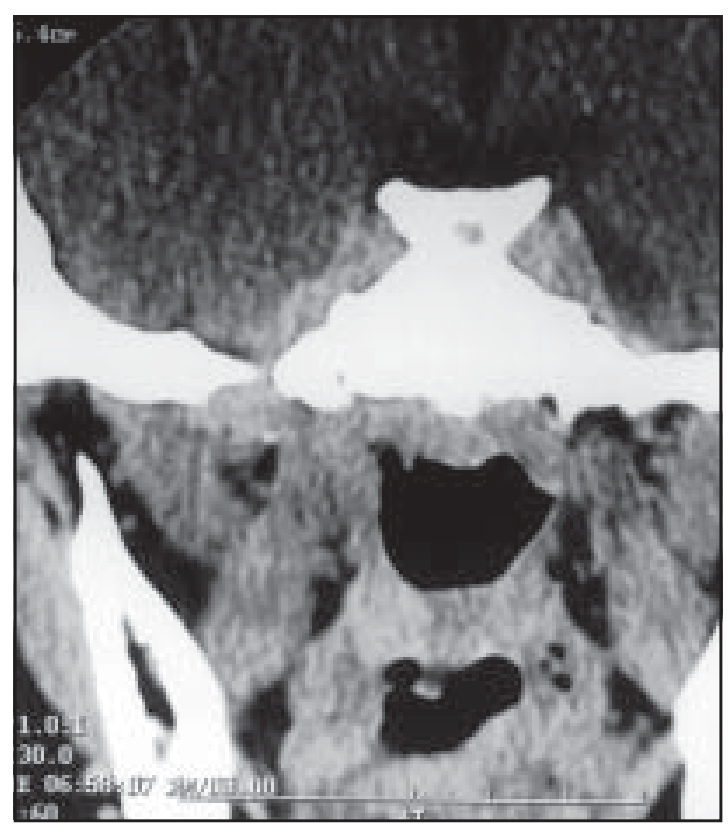

Figura 2. Tomografía axial computarizada de cavidades perinasales. Día 71. Persiste compromiso de seno cavernoso. cópica. Recibió también hidrocortisona para mejorar la tolerancia a la anfotericina, en relación a la cual presentó hipertensión arterial, que fue tratada con nifedipino primero y después con enalapril; la presión arterial se normalizó al suspender la corticoterapia. Además se usó una dosis de filgrastim (Neupogen $($ ) ) basados en que los neutrófilos tratados con este factor tienen, según la literatura médica consultada, mayor actividad contra Aspergillus sp, Candida sp y Mucor, por mejoría del estallido respiratorio del polimorfonuclear. ${ }^{5,6}$.

Una TAC de control efectuada al finalizar el tratamiento antifúngico, mostraba disminución importante del compromiso del seno cavernoso, aunque aún persistía (Figura 3). Completado el tratamiento se decidió el alta citándolo a control ambulatorio; sin embargo, el niño abandonó sus controles, logrando ser localizado sólo siete meses después. En una nueva evaluación se encontraba muy enflaquecido, emaciado y con una diabetes descompensada. Se comprobó una talla baja, T4 y TSH bajos y signos de hipogonadismo, que se consideraron debidas a hipofunción hipofisiaria, derivada de la severa desnutrición, a su vez secundaria al mal manejo de la diabetes. El examen neurológico era normal, excepto la leve

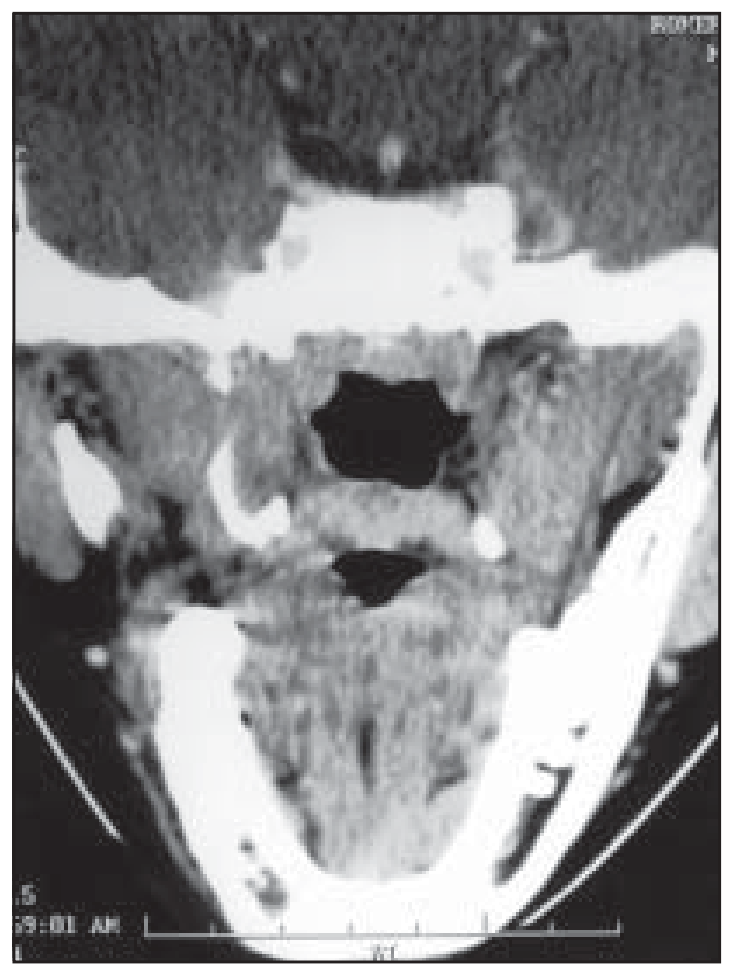

Figura 3. Tomografía axial computarizada de cavidades perinasales. Día 144. Fin de tratamiento. Menor compromiso de seno cavernoso, pero aún persiste. 


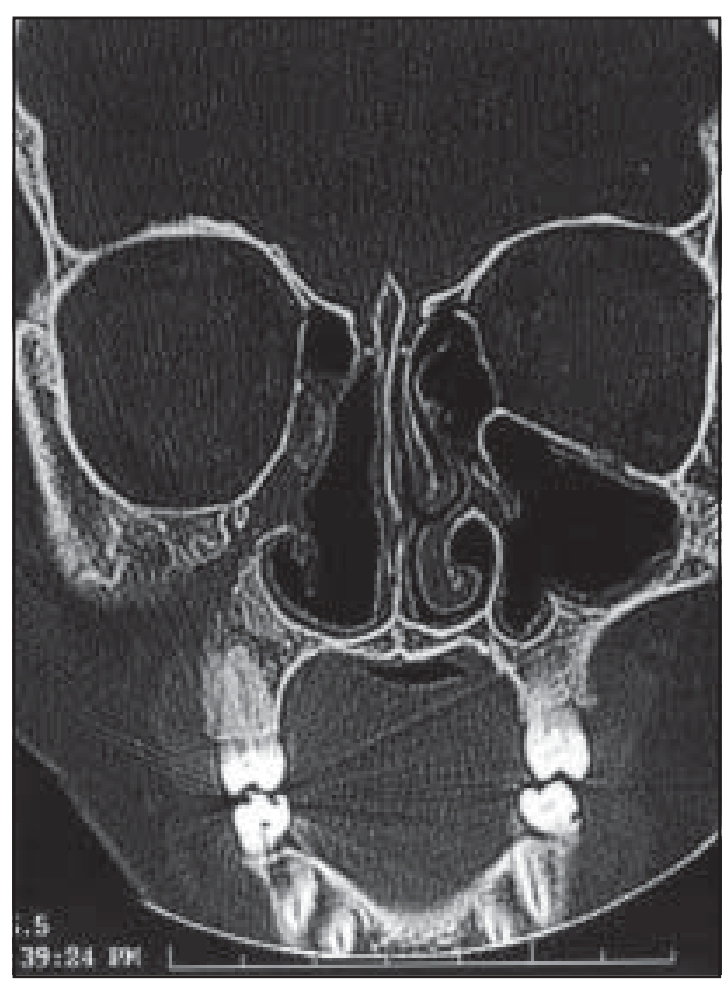

Figura 4. Tomografía axial computarizada de cavidades perinasales. Siete meses post tratamiento. Recuperación del piso de la órbita.

parálisis facial derecha, que presentara con anterioridad al proceso rinosinusal. Se le realizó otra TAC de CPN que no mostró evidencias de proceso inflamatorio y en la que destacaba la recuperación del piso de la órbita (Figura 4).

\section{Comentario}

Mucormicosis es una infección poco frecuente y por esto, poco conocida, lo que contribuye al retraso en el diagnóstico, como ocurrió en este paciente, en quien, a pesar de tener un factor de riesgo importante como diabetes mellitus mal controlada y una sinusitis sin respuesta a diversos esquemas antimicrobianos, el diagnóstico sólo se planteó después de 40 días de evolución.

Estos antecedentes y la experiencia del ORL en esta patología permitieron sostener el diagnóstico de mucormicosis rinocerebral planteado, aunque no fuera confirmado inicialmente, y decidir así terapia con anfotericina B.

A pesar del diagnóstico tardío, cuando ya existía compromiso intracraneano, en que el tratamiento quirúrgico agresivo recomendado era insostenible, la anfotericina B en dosis elevadas y los aseos quirúrgicos seriados por vía endoscópica consiguieron una respuesta clínica y de imágenes exitosa.

Con el uso de anfotericina B el paciente presentó elevación de la creatininemia y de la presión arterial, las que se normalizaron al suspender el tratamiento.

Es importante tener presente esta patología, especialmente si consideramos el aumento de la población de pacientes con factores de riesgo para tener esta infección, de manera de plantear el diagnóstico precozmente y ofrecer tratamiento oportuno.

\section{Resumen}

Se presenta el caso de un niño de 14 años, con diabetes mellitus sin control clínico adecuado, con un cuadro rinosinusal de evolución progresiva, sin respuesta a diversos esquemas antibióticos, en el que el diagnóstico de mucormicosis rinocerebral se planteó en forma tardía, cuando ya existía compromiso intracraneano, demostrado por tomografía. Considerado fuera de alcance quirúrgico, se trató con anfotericina $\mathrm{B}$ y aseos quirúrgicos seriados, vía endoscópica, con buena evolución clínica e imagenológica. El diagnóstico de mucor se comprobó mediante examen directo y estudio histopatológico que revelaron la presencia de hifas características.

\section{Bibliografía}

1.- Bernhard L. Wiedermann. Zygomycosis. En: R D, Feigin R D, Cherry J D. Textbook of Pediatric Infectious Diseases. $4^{\text {th }}$ edition. W B Saunders Company, Philadelphia 1998; 2354-60.

2.- www.emedicine.com. Rhinocerebral Mucormycosis Earhart K.C. (update 10 enero, 2003).

3.- Bravo M, Ferrer S, Etchard M, Trujillo S. Mucormicosis rinocerebral. Comunicación de 4 casos. Rev Méd Chile 1999; 127: 712-8.

4.- Shah P D, Peters K R, Reuman P D. Recovery from rhinocerebral mucormycosis with carotid artery occlusion: a pediatric case and review of the literature. Pediatr Infect Dis J 1997; 16: 68-71.

5.- Casadevall A, Pirofski L. Adjunctive immune therapy for fungal infections. Clin Infect Dis 2001; 33: 104856.

6.- García-Díaz J B, Palau L, Panckey G A. Resolution of rhinocerebral zygomycosis associated with adjuvant administration of granulocyte-macrophage colonystimulating factor. Clin Infect Dis 2001; 32: e166e170.

Correspondencia a:

Ana Chávez Polanco

E-mail: anachavez@mi.cl 